\title{
Combining innovation and sustainability: an educational paradigm for human development on earth
}

\author{
Ronaldo Mota ${ }^{1^{*}}$ and João FG Oliveira ${ }^{2}$
}

\author{
* Correspondence: \\ ronamota@gmail.com \\ ${ }^{1}$ Centro Universitário UNISEB \\ 14095-175 Ribeirão Preto, SP, Brazil \\ Full list of author information is \\ available at the end of the article
}

\begin{abstract}
Innovation is becoming more and more central in our society and it is directly associated to the possibility of sustainable economic and social development. In this new scenario, the educational institutions have increasingly assumed a relevant role for the innovation-based economic development. Consequently, education includes among its main missions collaboration for the promotion of a sustainable development with environmental preservation. Concerning the economic, social and environmental aspects, the economic pillar has been developed almost in an isolated manner, favouring more the financial aspects, less the social and almost ignoring the demands of the global environment. The potential conflict between development and preservation can be tackled through the stimulus for innovation, the correct use of new technologies and the dissemination through education, in all levels, of management methods based on the collaboration between schools, research teams, companies and society in general. A contemporary education, covering innovation solutions for a sustainable existence on our planet, has the chance to contribute to correct the adopted paths so far, so that the economic balance could be achieved with environmental preservation and social development. Sustainability defines how the humanity can meet its demands today without compromising the needs of future generation. It should be a guiding principle for world economic development and is closely depending on the way our population is educated to face such challenge. This paper presents a discussion on these aspects and proposes a framework of references to support its concept and implementation.
\end{abstract}

Keywords: Sustainability; Education; Innovation

\section{Springer}

(c) 2013 Mota and Oliveira; licensee Springer. This is an open access article distributed under the terms of the Creative Commons Attribution License (http://creativecommons.org/licenses/by/2.0), which permits unrestricted use, distribution, and reproduction in any medium, provided the original work is properly cited. 


\section{Resumo}

Inovação está se tornando cada vez mais central em nossa sociedade e está diretamente associada à possibilidade de um desenvolvimento econômico e social sustentável. Neste cenário, as instituições educacionais têm assumido um papel cada vez mais relevante no desenvolvimento econômico baseado em inovação. Consequentemente, educação inclui entre suas principais missões colaborar na promoção de um desenvolvimento sustentável com preservação ambiental. No que diz respeito aos aspectos econômicos, sociais e ambientais, o pilar da economia tem se desenvolvido muitas vezes de uma maneira quase isolada, priorizando os componentes financeiros, conferindo menos atenção às questões sociais e ignorando as demandas ambientais. Este potencial conflito entre desenvolvimento e preservação pode ser devidamente equacionado via estímulo à inovação, o correto uso de novas tecnologias e a disseminação pela educação, em todos os níveis, de métodos de gestão apropriados, baseados na colaboração entre escolas, pesquisadores, tecnólogos, empresas e sociedade em geral. Uma educação contemporânea, abrangendo soluções inovadoras para um desenvolvimento sustentável em nosso planeta, tem a chance de contribuir para corrigir os caminhos adotados até aqui, tal que um balanço econômico seja atingido de forma equilibrada com a preservação ambiental e o desenvolvimento social. O conceito de sustentabilidade está associado a como a humanidade pode satisfazer suas demandas hoje sem comprometer as necessidades das futuras gerações. Isso deve ser um princípio central para o desenvolvimento econômico e é extremamente dependente de como a população é educada para tal desafio. O presente artigo apresenta uma discussão sobre esses aspectos e propõe um cenário de referências para sua adequada implementação.

Palavras chave: Sustentabilidade; Educação; Inovação

\section{Background}

The global society has discussed intensely two important challenges: innovation and sustainability. They are the key aspects for a better global wealth distribution, however, how human beings can satisfy their needs without compromising future generations implies in significant changes in human behaviour only achievable by a new educational paradigm.

This paper defines, describes and discusses these two challenges, innovation and sustainability, combining them looking at a compatible approach to educate. The objective is to show the importance of considering these aspects for the development of a contemporary and appropriate way to teach and to learn. The contents are structured on the pillars of this new education paradigm in the following sections. In the discussion it is proposed a combination among innovation and sustainability as a new paradigm for education with the focus on new learning methods and intense international cooperation.

\section{Innovation}

Innovation is definitely everywhere and it is becoming increasingly central in our society (Mota 2009, 2011; Mota and Scott 2014). There is a long way from its initial concept in the Middle Ages meaning novelty, arising from human creativity, until today where it becomes a sort of emblem of modern society and directly associated to the possibility of sustainable economic and social development.

The concept of innovation is much broader than simply technological innovation, although the strong influence of the last one, especially along the nineteenth and twentieth 
centuries. Godin (2008) prefers to understand innovation as a category, which reflects a sort of dialectics between reality and language, in such a way that changes and events gave rise to new categories and these brought to light changes in the world, which contribute to a better clarification of the meaning of innovation.

The artisans during the Renaissance understood imitation as a good practice, closely associated with novelty-innovation, most of the times also considered as being invention itself. As pointed out by Newman (1989), by doing that it was an art learned by imitating nature, as claimed by the alchemists. Imitation was considered at that time as requiring work, experimentation, judgment and imagination.

It is interesting to observe that at the beginning of the industrial revolution in Britain, imitation was associated with invention because it could result in new commodities, introducing not only the real possibility to attend demands by diffusion and scale, but, by doing so, improving quality and design. Then, innovation by imitation, although not primary innovation, can be considered derivative or incremental innovation, which is different from copying.

The concept of innovation was always involved with the discussion about differences between discovery and invention. Discovery usually refers to finding facts or things that already exist, whilst invention is more associated to combining or making new things like objects, processes or new theories about something.

Invention, initially associated with science and also with imagination in literature and visual arts, over the last centuries become progressively identified with mechanical or technological invention (Engell 1981). Finally, during the twentieth century, because of the culture of things and utilitarian value, technological innovation became synonymous of invention and also very often of innovation.

The term innovation, although old (for instance, it is cited by Machiavelli in The Prince, 1513 and by F. Bacon in Of Innovations, 1625), was used only rarely before the twentieth century. In contrast, in the last century there was a series of debates about innovation. J.A. Schumpeter $(1939,1947,1961)$ wrote extensively about it. He argued that capitalism is a permanent creative destruction system and innovation is the cause of this phenomenon) (Mota and Scott 2013).

Schumpeter (1961) identified five types of innovation: 1) introduction of a new good; 2) introduction of a new method of production; 3) opening of a new market; 4) conquest of a new source of supply of raw materials; and 5) implementation of a new form of organization. Also, Schumpeter (1939) distinguished innovation from invention by saying that "innovation is possible without invention and invention does not necessarily induce innovation", only when commercialized.

During the second half of last century a number of authors (Deutsch et al. 1986; Mulgan et al. 2007) introduced a broader understanding of innovation including also "social innovation" meaning either major advances in the social sciences, policy reforms for the betterment of society or solutions to social needs, coming from community sectors among others.

More recently, a new wave of approaches for innovation includes original concepts like "open innovation", "democratizing innovation", "creative economies" and also areas not usually contained before like organizational and marketing innovation. All these elements are associated with a new characteristic that innovation comes also from many sources, not only the traditional research laboratories and include sometimes the users themselves. 
In the twentieth century, the general idea of a kind of "linear model" was consolidated, suggesting that innovation starts with basic research, then goes through applied research, then development, and finally production and diffusion. The last two steps have been assumed as more associated with innovation.

What can be observe today is that innovation is not anymore a possible distant consequence of the basic research or the end of the line. Innovation has become itself many times the origin of the research programmes, modulating and stimulating science to be produced as a consequence of the innovation word. At the same time, the traditional assumption that innovation results from meeting demands, nowadays is replaced by the idea that sometimes innovation generates demands never imagined before.

The following simplified knowledge management scheme can be proposed:

Modern Science (connected with technology and innovation, see below)

$\uparrow$ (scientific method)

General Knowledge

$\uparrow \quad$ (useful for education \& skills)

Systematic Information

$\uparrow$ (organization)

Basic Data (raw)

Regarding science, traditionally, the following straight line used to be assumed as the usual:

Science $\rightarrow$ Technology $\rightarrow$ Innovation

Nowadays, a different way is more convenient:

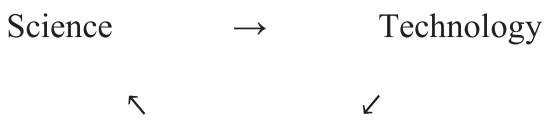

Innovation

Innovation is becoming more central, broader in concept, and it shares the role to be simultaneously the end and also the beginning of the process associated with knowledge or value creation.

Suh (2010) presented an interesting theory associating three laws as the necessary conditions for the occurrence of innovation. The first of them demands that all steps or elements of an innovation continuum must be present. The second law states that an innovation hub can be nucleated if the initial size of the nucleate is larger than a critical size and if the activation energy barrier for nucleation can be overcome. Finally, the last one requires that the nucleation rate must be faster than the rate at which innovative talents and ideas can diffuse away from the region.

The 2012 annual World Competitiveness Yearbook (WCY), which was recently announced, reflects how countries manage their economic and human resources to 
increase their prosperity. In accordance with them, the most competitive of the 59 ranked economies in 2012 are Hong Kong, the US and Switzerland. The results also permitted to conclude that emerging economies, like Brazil (ranked 48th), China (23rd), India (35th) and Russia (46th) are not yet immune to the recent international turmoil.

In this new scenario, the educational institutions have increasingly assumed and expanded a central role in science, technology and innovation-based economic development and the roles of universities and research centres have evolved from performing conventional research and educational functions to serving also as an innovationpromoting knowledge hub.

The traditional university, in general, looks backwards and assumes itself as a storehouse or accumulator of old knowledge. On the other hand, the modern university sees itself as a generator of new forms engaged with the advance of technological innovation and economic development in its region (Youtiea and Shapira 2008). In the context of innovation as a central issue, universities are simultaneously central generators, especially motivated by the external demands, and repositories of knowledge in our society. The way that knowledge is developed, disseminated and applied affects not only the cultural richness of the society, but also the global competitiveness.

The quest for a sustainable social and economical development and the challenges associated with competitiveness and the necessary closer understanding and joint work between the universities and the productive sector will demand new strategies for education in general and a deep discussion about the methodologies compatible with the formation of professionals in a scenario where innovation and sustainability are central.

\section{Methods}

\section{Sustainability}

The world faces today an enormous challenge to enable the development of human being's quality of life in our planet. The existing business models, which imply high levels of production, the current forms of city management and the available technological solutions are still far from allowing the less privileged societies to enjoy products and services providing greater comfort, culture and health impacts without causing irreparable damage to the environment.

The dimension of the problem can be better evaluated by the observation of the ecological footprint. The Ecological Footprint is defined as how much land and water area a human population requires to produce the resources it consumes and to absorb its waste (Seliger et al. 2008; Wackernagel 2006). It also tracks how much productive area-or biocapacity-is available. Figure 1, extracted from the Hong Kong Ecological Footprint Report $2013^{\mathrm{b}}$, specifies relevant aspects on how the human activity has developed in our planet. About one quarter of the earth's surface accounting for 11.3 billion hectares can be considered as biologically productive area contributing to the regeneration of resources. The global biocapacity per inhabitant on earth can be found by dividing the biologically productive available area by 6.15 billion people. The result is 1.8 global hectare per capita.

The curves in Figure 1 show humanity's total ecological footprint and the respective $\mathrm{CO}_{2}$ portion of it from 1961 to 2008. Since 1971, resource consumption on global level is higher than the ecological capacity. The global population has increased from 3.08 


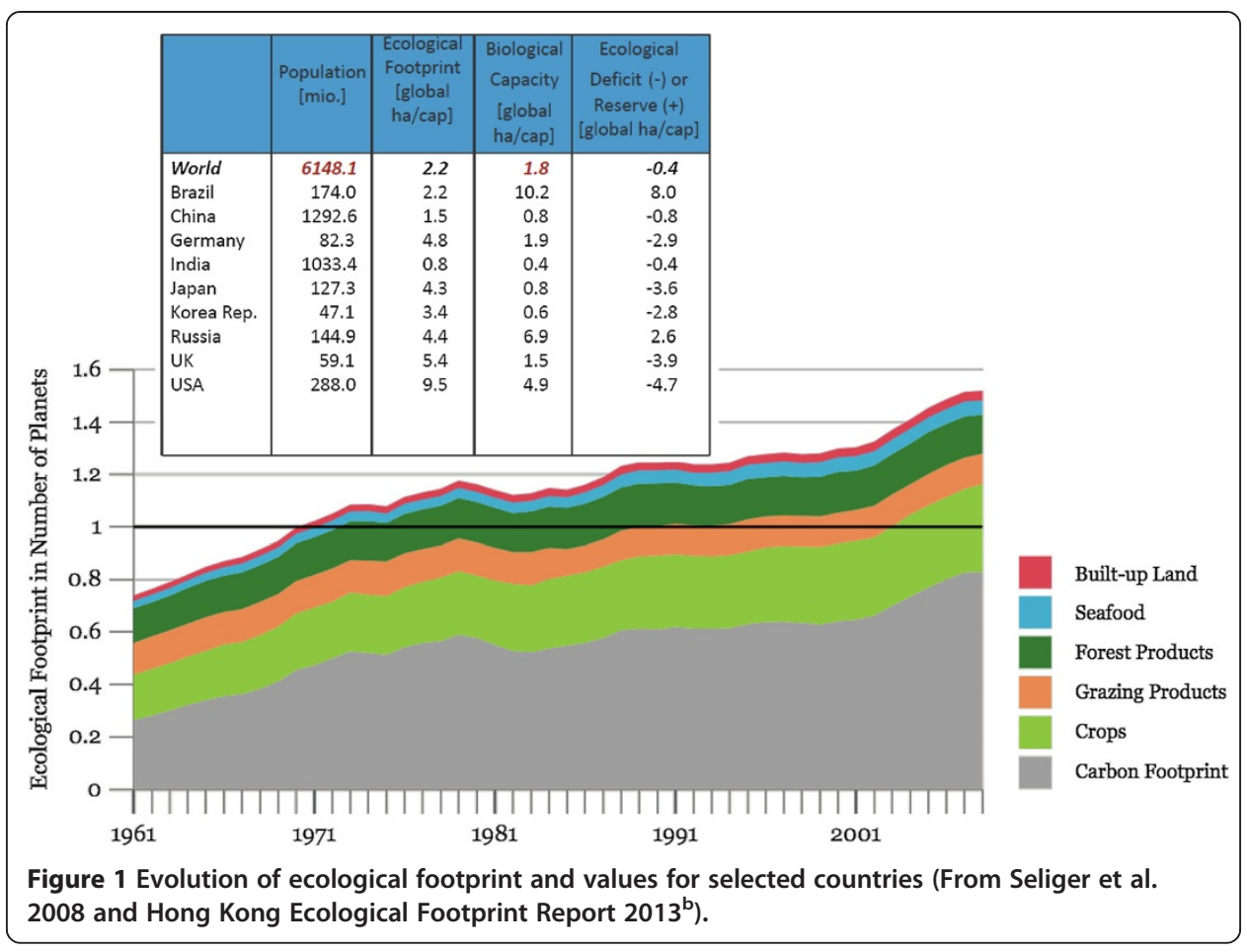

billions in 1961 to 6.15 billions in 2001. The total energy consumption in 2001 is more than seven times the amount in 1961.

The today's world average biocapacity per person of 1.8 hectare, ignoring the needs of wild species, is no longer sufficient for the human activity on earth. Today humanity uses the equivalent of 1.5 planet to provide the resources we use and absorb our waste. This means it now takes the Earth one year and six months to regenerate what we use in a year. This metric allows us to calculate human pressure on the planet and come up with facts, such as: if everyone lived the average North American lifestyle we would need five Earths to provide all the required resources.

The problem becomes dramatic if the future development of poorer nations is considered in the scenario. Figure 2, extracted from the Hong Kong Ecological Footprint Report $2013^{\mathrm{b}}$, shows the ecological footprint values compared with the UN Human Development Index - HDI. As it can be seen in the chart, most of African and many Asian and Latin American countries present a favourable ecological footprint but at the same time have a low HDI.

This means: if these countries are searching for better life quality and eager to develop their economies based on the same model used by North American or European countries, the planet will get its biocapacity too overloaded making human life on earth unviable.

So we need to find a new sustainable development model, since we can't have a larger fraction of the global population living with high consumption patterns of products intensive in natural resources or unplanned for recycling, remanufacturing or reuse. Finally, our world would not stand to promote more equal income distribution based on the current development model, as set out in the major economies, whose success favours the consumption, income, but less the environment and, consequently, man. 


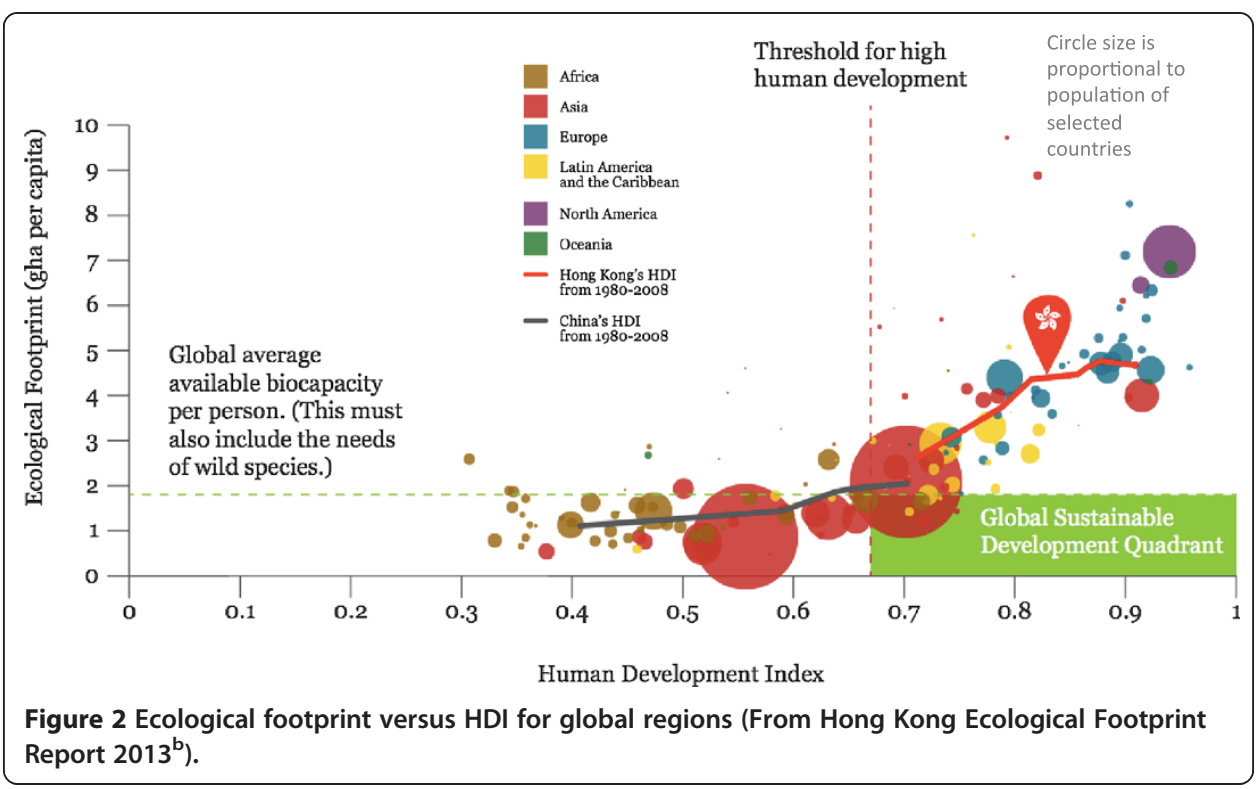

Surely, the greatest challenge of sustainability is to articulate the promotion of social development with environmental preservation. The third pillar, economic, has been developed almost in an isolated manner, favouring more the financial aspects, less the social and almost ignoring the demands of the global environment.

The planet no longer supports the current levels of consumption without a precise planning based on the essential sustainability tripod. The conflict between development and preservation can be solved through the use of new technologies and management methods to ensure their dissemination, collaboration between research teams, companies and institutions, providing an equilibrium on the different expectations: economic, social and environmental.

On the other hand, innovation in technology, business and management has become key to business success. Governments encourage institutions and businesses by providing programs and funding mechanisms to increase their competitiveness by doing innovation. Innovation has become the salvation word in the short and medium term, to keep companies alive and therefore people jobs.

The solution to the huge challenge of sustainability is the deep understanding of the involved technologies, the management methods, as well as the tools for analysis and compatible education, among other associated elements. Innovation should be the protagonist enabler for human life quality on our planet. For this, the innovation process must include substantially the sustainability goals, balancing not only the success of a business or marketing idea, but also their feasibility and environmental benefits to the human race.

The framework proposed in this article shows the only feasible way to a methodological change in the medium and long-term direction of development on our planet: the search for knowledge in university groups in international cooperation that address the challenges and solutions for sustainable innovation in their teaching syllabus and learning methodologies. Only a contemporary education, covering innovation solutions for a sustainable existence on our planet, has the chance to correct the adopted paths so far, so that the economic balance could be achieved with environmental preservation and social development. 
In this case, the proposed circular knowledge management scheme is not only a modern path for science development based on innovation needs, but more than this, its is the only way to develop sustainable solutions for allowing the continuity of humans in our planet with less social stress, misery or even terror.

The two foundations of innovation and sustainability should be combined in a new education system that can form a new generation of citizens able to manage business and governments along these huge challenges. The education system must be the foundation for building the necessary society, which must manage the innovation process through a more sustainable world.

It is known that sustainable innovation require minds able to break old paradigms with creativity, motivation and independence from well-established models. So, new learning processes are also the key for succeeding with the enormous present global challenges (Mota and Scott 2014).

\section{Educational paradigm}

Education has been assumed for a long time as contributing to the individual, to the common good and to the community/regional/national prosperity. Today, more than ever, education is becoming critically important, in face of new economic, environmental, and social challenges. The world is changing and education is becoming more relevant, but basically education is following behind trying to adjust it to the new scenarios. The great recent change is the role played by innovation and sustainability on the social and economics scenes.

Students will only be able to meet future challenges as long their schooling and informal learning activities could prepare them for adult roles simultaneously as citizens, employees, managers, parents, entrepreneurs etc. Education has increasingly assuming broader role to play, making teaching and learning more complexes activities. It means that to achieve their full potential as adults, students need to be stimulated to develop a range of skills and knowledge that facilitate mastery and application of traditional subjects as reading, writing, mathematics and sciences, but also includes nowadays demands associated to skills such as problem solving, critical thinking, interpersonal communication, collaboration, and other contemporary capabilities.

There is a new demand asking to schools to take care also of elements like creativity, innovation, and ethics, which, in fact, may also be developed in informal learning environments. To educate not only became more complex but now there are, at least, three different domains demanding a deep understanding of each one of them: the more traditional cognitive domain and, additionally, intrapersonal and interpersonal domains (NRS, 2011) ${ }^{\mathrm{c}}$.

Contemporary education must take into account the collaboration towards the promotion of a sustainable development with environmental preservation. This potential conflict between development and preservation can be tackled through the stimulus for innovation and the correct use of new technologies and management methods to ensure their dissemination through education, in all levels, based on the collaboration between schools, research teams, companies and society. The conjugation of education and innovation can help to provide the necessary equilibrium on the essential sustainability tripod: economics, social and environmental. 
Internationalisation in education and innovation is directly associated with a process that prepares the academic community, involving students, teachers and researchers, as well as the entrepreneurs, for successful participation in an increasingly globalised and interdependent planet. Even taking into account that the above considerations are widely accepted, internationalization implies specific approaches and strategies to different institutions, countries or stages.

The necessity for internationalisation is, in general, understood as an essential and complementary ingredient to appropriately form professionals and also to be taken into account with respect to innovative enterprises able to face the challenges of contemporary world and to ensure the country's economic, scientific and technological competitiveness.

Internationalisation of education is becoming a common phenomenon around schools all over the planet and acting as a way to prepare students with the necessary capabilities to face the globalized world of the 21st century. To achieve such goals, many programmes have been established recently, especially those connecting education and innovation, with a deep impact on the education institutions, particularly Universities and Colleges, demanding inclusion of this theme in all mission statements.

Policies like the establishment of goals on the percentage of foreign students and recruitment of faculty with international experience have been implemented in many countries simultaneously. Similarly, stimulus to cross-cultural programmes, increasing on the academic mobility and more concerns about content on the curriculum, including intercultural and multicultural education are clear symptoms that these issues are much more important today than they used to be considered a few decades before (Knight 1994).

Concerning international student mobility, the International Baccalaureate (IB) Foundation $^{\mathrm{d}}$, established in Switzerland at the end of the 1960's, intended initially to be concentrated in preparing schools with a curriculum and diploma qualification recognized by universities around the world (Bunnell 2010). The IB mission has expanded seeking to make the IB education compatible with the demands of the new global reality and also available to students of all ages. In accordance with the IB site, eight criteria help to define "international education" nowadays: (1) developing citizens of the world in relation to culture, language and capacity to live among people of other nations; (2) building and reinforcing student's sense of identity and cultural awareness; (3) fostering student's recognition and development of universal human values; (4) stimulating curiosity and inquiry in order to foster a spirit of discovery and enjoyment learning; (5) equipping students with skills to learn and acquire knowledge, individually or collaboratively, and to apply these skills and knowledge accordingly across a broad range of areas; (6) providing international content while responding to local requirements and interests; (7) encouraging diversity and flexibility in teaching methods and (8) providing appropriate forms of assessment and international benchmarking.

With respect to the last criterion above presented, Yemini (2012) has proposed that the internationalisation in schools should involves important goals which can be summarized as: (1) evaluating teachers', students' and other stakeholders' opinions, attitudes and beliefs on a range of learning opportunities; (2) monitoring internationalization activities in schools according to the proposed framework together with validity studies; (3) mapping the gaps in teacher training in order to identify and develop generic skills and competencies related to internationalization; (4) expanding this course of study in the context of different populations in developed and developing countries; (5) 
secondary analysis of schools with diverse levels of internationalization to identify parameters that assist and encourage this phenomenon; and (6) long-term follow-up of students and teachers to track transformations in their views of internationalization.

\section{Discussion}

The introduction of the international dimension into the educational institutions affects a larger number of individual students, teachers and researchers, and goes beyond them. It is a phenomenon deeply connected with meeting new demands coming from a globalized society that is increasingly modulating the way we teach and learn, requiring new methodologies.

Concerning new methodologies, Mota and Scott (2014) have presented independent learning as an appropriate strategy and an open fresh opportunity to prepare students, contributing to the formation of professionals able to face the challenges associated with a new scene where innovation and entrepreneurship are central priorities.

Also, there are new challenges to be globally faced, among them how to educate for innovation taking into account the demands for sustainability. This particular concern is huge, since education, innovation and sustainability are complexes issues, demanding attention to the rapid dynamics with the way knowledge is produced and transferred nowadays. The CDIO $^{\text {tw }}$ INITIATIVE $^{\mathrm{e}}$ is a good example on how this can be articulated for the case of Engineering. It is presented as "an innovative educational framework for producing the next generation of engineers". The system provides an education system composed of syllabus and methods stressing engineering fundamentals set in the context of Conceiving - Designing - Implementing - Operating real-world systems and products. Many important engineering institutions, such as MIT, Delft University, and California State University have been adopted it as the framework of their curricular planning and outcome-based assessment.

The main features of CDIO are not only the contents and methods but also the intense international cooperation in an open system that accepts new members who will train the engineers of the future. The exchange with the experiences from other countries in different cultures, with the openness of information and the use of internet combined with the high motivation hands on methods are the key for the success of this system. In a similar way, a global framework initiative not only for engineers but with focus on the innovation and sustainability values could be the key for a new educational paradigm able to built a next generation of citizens capable of building a sustainable society, which will have a better wealth distribution all over the world.

In this new educational framework, the incentive on innovation based on independent learning, the high level of awareness about the earth sustainability issues and the global coverage with intense international cooperation can be the starting point for building a better society through education.

\section{Conclusion}

Innovation, sustainability and education are strongly connected. An educated workforce is essential to a country's competitiveness and productivity. As pointed out by Mota and Scott (2014), workers who have received little formal education can accomplish only simple manual tasks and find it almost impossible to adapt to more complexes 
production processes and techniques. Consequently, lack of education becomes a constraint on business development, making extremely difficult to produce sophisticated or value-intensive products, which depend on existing human resources.

A knowledge management scheme was presented and the traditional straight line connecting science, technology and innovation was proposed to be replaced by a circle, where innovation is simultaneously the end and the beginning of the knowledge creative process. It was also discussed that, despite the essential roles the traditional education systems have played, they are not enough anymore to face the challenges ahead and capable to answer to new needs. The contemporary trends suggest that future professional activities involve dealing with complex problems, sometimes in careers and jobs still to be created. The traditional educational methods are, in general, only prepared for the routine tasks and existing jobs, requiring new approaches able to stimulate creativity and autonomy skills, which are essential to the present and future innovation and sustainability demands.

Quality higher education is definitely strategic for economies competing beyond simple production processes and products in a globalized economy increasingly requiring innovation and well-educated workers, able to perform complex tasks and adapt rapidly to new technologies and the new demands of the economy.

The presence of quality higher education institutions and excellent scientific research laboratories generate the basic knowledge needed to build the new scenario where innovation and sustainability are central priorities and main targets. Extensive collaboration between academia and enterprises provides technological developments able to face the high levels of competition, which will be crucial for sustainable growth in the contemporary society.

Innovation can emerge from knowledge, which can be closely related to the know-how, skills, working conditions and technological breakthroughs that are embedded in organizations. The basis of many of the productivity gains that our economies have historically experienced has been shown to depend from technology and compatible education. This assumption is correct for the industrial revolution in the 18th century, the invention of the steam engine and the generation of electricity. Nevertheless, the more recent digital revolution makes it clearer than ever the extreme dependence on education and innovation to provide a social and economical sustainable development.

Sustainability defines how the humanity can meet its demands today without compromising the needs of future generations. It should be a guiding principle for world economic development and is closely depending on the way our population is educated to face such challenge. The best way to associate economic development with sustainable social development is to incorporate innovation as a tool to become increasingly environment-friendly. In summary, it is increasingly becoming clear that the key to progress compatible with sustainability, particularly in times of economic crisis, is innovation associated with education.

A new framework system based on these pillars should be the only solution for building a society where the main values are related to a more sustainable world and a better wealth distribution.

\section{Endnotes}

${ }^{a}$ WCY, World Competitiveness Yearbook 2012. As can be seen in: http://www.imd.org/ news/IMD-announces-its-2012-World-Competitiveness-Rankings.cfm. Accessed July 2012. 
${ }^{\mathrm{b}}$ The Hong Kong Ecological Footprint Report 2013. As can be seen in: http://www. footprintnetwork.org/images/article_uploads/hong_kong_ecological_footprint_report_ 2013.pdf. Accessed August 2013.

${ }^{\mathrm{c}}$ NRS, National Research Council, 2011. Assessing 21st century skills: Summary of a workshop. J.A. Koenig, Rapporteur. Committee on the Assessment of 21st Century Skills. Board on Testing and Assessment, Division of Behavioral and Social Sciences and Education. Washington, D.C.: National Academies Press. Available in http://www. nap.edu/catalog.php?record_id=13215. Accessed August 2012.

${ }^{\mathrm{d}}$ IB-International Baccalauraureate. As seen in: http://www.ibo.org/general/who.cfm. Accessed August 2012.

${ }^{\mathrm{e}} \mathrm{CDIO}$, Conceiving, Designing, Implementing and Operating real-world systems and products, 2012. As seen in: http://www.cdio.org. Accessed August 2012.

Competing interests

Both authors declare that they have no competing interests.

\section{Authors' contributions}

Both authors have participated equally along all the stages and both read and approved the final manuscript.

\section{Acknowledgments}

One of the authors, Ronaldo Mota, would like to acknowledge the Brazilian Agency CAPES for the Fellowship associated with the "Cátedra Anísio Teixeira" at the Institute of Education-University of London. The authors also would like to thank the Brazilian Agency CNPq for financial support.

\section{Author details}

${ }^{1}$ Centro Universitário UNISEB, 14095-175 Ribeirão Preto, SP, Brazil. ${ }^{2}$ Engineering School of São Carlos, University of São Paulo, 13566-590 São Carlos, SP, Brazil.

Received: 29 July 2013 Accepted: 13 September 2013

Published: 22 January 2014

\section{References}

Bunnell T (2010) The international baccalaureate and a framework for class consciousness: the potential outcomes of a "class-for-itself". Discourse Stud Cult Polit Ed 31(3):351-361

Deutsch et al (1986) Advances in the social sciences, 1900-1980: what, who, where, how. Abt Books, Cambridge, Mass Engell J (1981) The creative imagination: enlightenment to romanticism. Harvard University Press, Cambridge, Mass Godin B (2008) Innovation, the history of a category. Project on the intellectual history of imitation. Working paper no. 1. INRS, Quebec

Knight J (1994) Internationalization: elements and checkpoints. Research monograph, no. 7. Canadian Bureau for International Education, Ottawa, Canada

Mota R (2009) Inovação tecnológica: desafios e perspectivas. Educação Brasileira 31:61-80

Mota R (2011) O papel da inovação na sociedade e na educação. In: Colombo S, Rodrigues GM (eds) Desafios da sociedade contemporânea. ARTMED, Porto Alegre, pp 459-474

Mota R, Scott D (2014) Educating for innovation and independent learning. Elsevier, Oxford, in press

Mulgan et al (2007) In and out of sync: the challenge of growing social innovations, technology and the arts (NESTA). National Endowment for Science, London

Newman W (1989) Technology and alchemical debate in the late middle ages. Isis 80(3):423-445

Seliger G, Him H-G, Kernbaum S (2008) Approaches to sustainable manufacturing. Int J Sustainable Manuf 1:1-2

Shumpeter JA (1939) Business cycles: a theoretical, historical, and statistical analysis of the capitalism process. McGraw-Hill, New York

Shumpeter JA (1947) The creative response in economic history. Journal of Economic History, November, pp 149-159

Shumpeter JA (1961) The theory of economic development: an inquiry into profits, capital, credit, interest, and business cycle. Translated from German by redvers opie. OUP, New York

Suh NP (2010) A theory of innovation and case study. Int J Innov Manage 14:893-913

Wackernagel M (2006) Ecological footprint accounting. In: Keiner M (ed) The future of sustainability. Springer, Netherlands

Yemini M (2012) Internationalization assessment in schools: theoretical contributions and practical implications. J Res Int Ed 11(2):152-164

Youteia J, Shapira P (2008) Building an innovation hub: a case study of the transformation of university roles in regional technological and economic development. Res Policy 37:1188-1204

doi:10.1186/2196-288X-1-2

Cite this article as: Mota and Oliveira: Combining innovation and sustainability: an educational paradigm for human development on earth. Brazilian Journal of Science and Technology 2013 1:2. 